\title{
Bulletin bibliographique
}

\section{(2) OpenEdition \\ 1 Journals}

Édition électronique

URL : https://journals.openedition.org/philosant/2859

DOI : 10.4000/philosant.2859

ISSN : 2648-2789

Éditeur

Éditions Vrin

\section{Édition imprimée}

Date de publication : 13 novembre 2009

ISBN : 978-2-7574-0124-8

ISSN : 1634-4561

\section{Référence électronique}

« Bulletin bibliographique », Philosophie antique [En ligne], 9 | 2009, mis en ligne le 25 juillet 2019 consulté le 05 décembre 2022. URL : http://journals.openedition.org/philosant/2859 ; DOI : https:// doi.org/10.4000/philosant.2859

\section{(c) (†) $\odot$}

Creative Commons - Attribution - Pas d'Utilisation Commerciale - Pas de Modification 4.0 International - CC BY-NC-ND 4.0

https://creativecommons.org/licenses/by-nc-nd/4.0/ 


\section{Bulletin Bibliographique}

Éditions, traductions et commentaires

- Aristote, Météorologiques. Traduit du grec par Pierre Thillet. Édition établie, présentée et annotée par Pierre Thillet, Paris, Gallimard, 2008 (Tel, 356).

Traduction française avec en regard le texte grec établi par F.H. Fobes (Cambridge, Mass., 1919, réimpr. Hildesheim, 1967), précédée d’une introduction détaillée (p. 9-62) et suivie de sept appendices : Éditions et traductions du texte grec; Tableau des hapax aristotéliciens ; Tableau des manuscrits ; Tableau de correspondance entre le latin et l'arabe ; Bibliographie (p. 421-449); Notes (p. 450-603) ; Index des noms.

- Porphyre, Commentaire aux Catégories d'Aristote. Édition critique, traduction française, introduction et notes par Richard Bodéüs, Paris, Librairie philosophique J. Vrin, 2008 (Bibliothèque des textes philosophiques).

- Plotin, Traités 45-50 (45. L'éternité et le temps. 46. Sur le bonbeur. 47-48. Sur la providence. 49. Sur les hypostases qui connaissent et sur ce qui est au-delà. 50. Sur l'amour). Présentés, traduits et annotés par M. Guyot, Th. Vidart, R. Dufour, F. Fronterotta et J.-M. Flamand, sous la direction de L. Brisson et J.-F. Pradeau, Paris, Éditions Flammarion, 2009 (GF 1401).

- Plotin, Traité 2 (IV, 7). Introduction, traduction, commentaires et notes par Angela Longo, Paris, Éditions du Cerf, 2009 (Les Écrits de Plotin).

Études

- Gaetano Licata, Teoria platonica del linguaggio : prospettive sul concetto di verità. Presentazione di Giuseppe Nicolaci, Gênes, Il Melangolo, 2007 (Università, 87).

Cette étude se propose de retrouver le sens du concept de rectitude/vérité des noms et de montrer qu'il continue de jouer un rôle décisif dans les théories contemporaines de la signification. La première partie de l'ouvrage, portant sur la conception platonicienne du logos, offre un véritable commentaire du Cratyle, et la seconde partie, une théorie de la signification fondée sur cette conception.

- Pascal Mueller-Jourdan, Une initiation à la philosophie de l'Antiquité tardive : les leçons du Pseudo-Élias, Paris-Fribourg, Éditions du Cerf-Academic Press, 2007 (Vestigia).

- Aldo Lo Schiavo, Platone e le misure della sapienza, Naples, Bibliopolis, 2008 (Saggi Bibliopolis, 95).

- Julie Giovacchini,Épicure, Paris,Les Belles Lettres, 2008 (Figures du Savoir).

- Hervé Barreau, Aristote pour aujourd'bui et pour demain, Chennevières-surMarne, Éditions Dianoïa, 2008 (Philosophia perennis).

- Leone Gazziero, Rationes ex machina. La micrologie à l'âge de l'industrie de l'argument, Paris : Librairie philosophique J. Vrin, 2008 (Problèmes \& Controverses).

- Michael Bowler, Heidegger and Aristotle: Philosophy as Praxis, Continuum International Publishing Group, Londres-New York, 2008 (Continuum Studies in Continental Philosophy).

- Emmanuelle Rousset, Les Intermittences de l'être : lecture du Sophiste de Platon, Lagrasse, Éditions Verdier, 2009. 
- Alexis Pinchard, Les langues de sagesse dans la Grèce et l'Inde anciennes, Genève, Librairie Droz, 2009 (École pratique des hautes études. Hautes Études du Monde Géco-Romain, 43).

- Jeremy Kirby, Aristotle's Metaphysics: Form, Matter and Identity, Continuum International Publishing Group, Londres-New York, 2009 (Continuum Studies in Ancient Philosophy).

- Riccardo Chiaradonna, Plotino, Rome, Carocci Editore, 2009 (Pensatori, 3).

- Giovanni Casertano, I Presocratici, Rome, Carocci editore, 2009 (Pensatori, 4).

- Maria Michela Sassi, Gli inizi della filosofia : in Grecia, Turin, Bollati Boringhieri, 2009 (Nuova Cultura. Introduzioni, 208).

- Mario Vegetti, "Un paradigma in cielo ». Platone politico da Aristotele al Novecento, Rome, Carocci editore, 2009 (Saggi, 50).

- Federico Zuolo, Platone e l'efficacia. Realizzabilità della teoria normativa, Sankt Augustin, Academia Verlag, 2009 (Collegium Politicum. Contributions to Classical Political Thought).

Recueils

- Laurence Boulègue \& Carlos Lévy (éd.), Hédonismes : penser et dire le plaisir dans l'Antiquité et à la Renaisance, Villeneuve d'Ascq, Presses Universitaires du Septentrion, 2007 (Cahiers de philologie, vol. 23. Série Apparat critique).

- Maria Michela Sassi (éd.), Tracce nella memoria : teorie della memoria da Platone ai moderni, Pise, Edizioni della Normale, 2007.

- Michèle Broze, Baudouin Decharneux, Sylvain Delcomminette (éd.),'A $A \lambda$ '

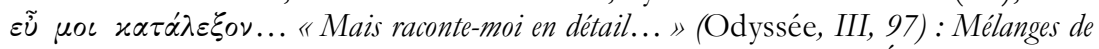
philosophie et de philologie offerts à Lambros Couloubaritsis, Bruxelles, Éditions OusiaParis, Librairie philosophique J. Vrin, 2008.

- Livio Rossetti \& Alessandro Stavru (éd.), Socratica 2005 : studi sulla letteratura socratica antica presentati alle Giornate di studio di Senigallia, Bari, Levante editori, 2008 (Le Rane, 52).

Contributions de A. Alderman, L. Bargeliotis, G. Casertano, F. Dinapoli, E. Grasso, A. Hourcade, M. Narcy, H.-O. Ney, N. Notomi, L. Rossetti, S. Schorn, K. Sharp, E. Spinelli, A. Stavru, F. Trabattoni, M. Tulli, M. Vegetti.

- Francesca Alesse, Francesco Aronadio, Maria Cristina Dalfino, Luca Simeoni, Emidio Spinelli (éd.), Anthropine sophia: studi di filologia e storiografia filosofica in memoria di Gabriele Giannantoni, Naples, Bibliopolis, 2008 (Elenchos, 50).

Dix ans après la disparition de G. Giannantoni, cinq de ses élèves ont pris l'initiative de rappeler son souvenir avec ce volume, le cinquantième de la collection par lui fondée. Le volume rassemble trente-trois contributions dont les thèmes vont du ve siècle av. J.-C. au XVI e apr. J.-C.

- Henri Hugonnard-Roche (éd.), L'enseignement supérieur dans les mondes antiques et médiévaux : aspects institutionnels, juridiques et pédagogiques, Paris, Librairie philosophique J. Vrin, 2008 (Textes et traditions, 16). 